\title{
QUAL O LUGAR DE CECÍLIA MEIRELES NA POESIA BRASILEIRA?
}

Gustavo Henrique Rückert

Resumo: Este artigo tem como objetivo investigar qual o lugar de Cecília Meireles na história da poesia brasileira. Nesse intuito, algumas das principais historiografias literárias do país são abordadas a fim de analisar que imagem de nação elas constroem. Alguns poemas paradigmáticos para essas historiografias são comparados com poemas de Cecília Meireles com o objetivo de compreender quais aspectos de sua lírica divergem da imagem hegemônica veiculada pelas historiografias. Os resultados apontam para a importância do mar como elemento poético de sua obra, configurando uma poesia do deslocamento e da viagem. Desse modo, conclui-se que o lugar de Cecília não é necessariamente o lugar de uma poesia nacional, mas o lugar de uma poesia transnacional, marcada pelo fluxo e pelo contato com diferentes tradições literárias.

Palavras-chave: Cecília Meireles. Poesia brasileira. Século XX.

Abstract: This paper aims to investigate the place of Cecilia Meireles in the history of Brazilian poetry. In this sense, some of main literary historiographies of the country are approached in order to analyze what image of nation they narrate. Some paradigmatic poems for these historiographies are compared with poems by Cecília Meireles in order to understand which aspects of her lyric differ from the hegemonic image conveyed by historiographies. The results point to the importance of the sea as a poetic element in her work, configuring a poetry of displacement and travel. Thus, it is concluded that Cecilia's place is not necessarily the place of national poetry, but the place of transnational poetry, marked by flow and contact with different literary traditions.

Keywords: Cecília Meireles. Brazilian poetry. 20th century.

Para Ana Mafalda Leite

Escrever sobre Cecília Meireles é sempre desafiador, dada sua multiplicidade. Nascida em 1901, no Rio de Janeiro, Cecília não foi apenas poeta, como também uma das mais 
destacadas intelectuais brasileiras do Século XX. Foi cronista dos principais veículos de imprensa brasileiros. Na década de 1930, foi uma das defensoras da reforma do ensino no Brasil, advogando a liberdade, a inteligência e a experimentação científica como valores pedagógicos. Foi autora de livros didáticos e de literatura infantil para uso escolar. No Rio de Janeiro, onde atuou como professora da Escola Normal, fundou a primeira biblioteca infantil da cidade. Sofreu censura da ditadura do Estado Novo, tendo a biblioteca fechada por Getúlio Vargas. Tornou-se uma importante voz crítica do Estado Novo brasileiro. Lecionou Literatura Luso-Brasileira e Crítica Literária na extinta Universidade do Distrito Federal do Rio de Janeiro. Lecionou Literatura Brasileira na Universidade de Austin, no Texas. Foi agraciada com o título de doutora honoris causa pela Universidade de Delhi, na Índia. Promoveu cursos e palestras em diferentes países, como México, Holanda e Índia. Traduziu obras de Rainer Maria Rilke, Virginia Woolf, García Lorca, entre outros. Manteve laços com escritores portugueses, inclusive com Fernando Pessoa, com quem se correspondeu por cartas. Escreveu obras de crítica literária (sobre literatura infantil, literatura brasileira e literatura portuguesa). Escreveu sobre cultura afro-brasileira, brasileira e açoriana (sua avó materna era natural dos Açores). Escreveu peças de teatro e 
contos. Aventurou-se na pintura. Estudou filosofia. Foi uma das primeiras poetas brasileiras a rejeitar o termo poetiza em função da discriminação de gênero, promovendo (ao lado de outras escritoras) uma discussão bastante inédita a respeito da questão no início do século XX (COELHO, 2001; DALFARRA, 2006; SILVA, 2009).

Na poesia, publicou mais de vinte obras (sem contabilizar as publicações póstumas). Seu trabalho lírico é bastante diversificado, perpassando o parnasianismo/simbolismo de Espectrus (1919); a solidão e a introspecção de Nunca mais e poema dos poemas (1923); o tom filosófico de Vaga música (1942); os versos destinados ao público infantil de Criança, meu amor (1923) e Ou isto ou aquilo (1964); o resgate da literatura medieval (sobretudo Amadis de Gaula) nos poemas de Amor em Leonoreta (1952); o épico sobre o movimento político/poético da Inconfidência Mineira em $O$ romanceiro da inconfidência (1953); o olhar viajante de obras como Poemas escritos na Índia (1953) ou os Poemas de Israel (1963); religiosos como o Pequeno oratório de Santa Clara (1955); modernos e atentos ao cotidiano, como em Viagem (1939), Mar absoluto (1945) e Metal Rosicler (1960); com um toque de erotismo descritivo em Canções (1956). Ainda com todas essas características, seria possível prosseguir com outras e muitas facetas de sua poesia. 
Mas qual seria o lugar dessa poeta tão múltipla na poesia brasileira? Inicialmente, é importante pontuar que Cecília é um nome que podemos afirmar canônico na literatura brasileira. É raro, por exemplo, a existência de historiografias literárias, livros didáticos ou ementas acadêmicas que não a mencionem $^{1}$. Relativamente frequente no cotidiano do país, seu nome é atribuído a escolas, bibliotecas, ruas e praças. No entanto, os poetas paradigmáticos na representação da poesia brasileira, em historiografias literárias, livros didáticos e ementas de universidades, geralmente são Carlos Drummond de Andrade, Manuel Bandeira e João Cabral de Melo Neto - todos contemporâneos de Cecília, a quem raramente é atribuída tal relevância.

O início do século XX é tomado como o momento mais decisivo da literatura nacional para muitas historiografias do país, para o sistema escolar e para movimentos artísticos da segunda metade do século XX (Concretismo, Tropicalismo e Cinema Novo, por exemplo). Na narrativa historiográfica construída por esses diferentes textos,

1 Algumas historiografias foram consultadas para esta pesquisa: Evolução da poesia brasileira (1932), de Agrippino Grieco; Apresentação da poesia brasileira (1946), de Manuel Bandeira; A literatura no Brasil (1955), organizada por Afrânio Coutinho; Presença da literatura brasileira (1964), de Antonio Candido e José Castello; História concisa da literatura brasileira (1970), de Alfredo Bosi; História da literatura brasileira (2001), de Massaud Moisés; Formação da literatura brasileira (1959), de Antonio Candido. Esta última, embora o recorte temporal não abranja o século XX, não deixa de citar Cecília em seu diálogo com os poetas árcades. Também foi consultado Vanguarda europeia \& Modernismo brasileiro (1973), publicação em que Gilberto Teles elenca os mais decisivos textos das vanguardas e dos modernismos do fim do século XIX ao início do século XX. 
a literatura brasileira é aparentemente dividida entre antes e depois do Modernismo de 22 (FISCHER, 2013). Desse modo, o movimento é tomado como uma espécie de mito fundacional de uma literatura nacional ${ }^{2}$. É claro que, nos Séculos XVIII e XIX, as escolas árcade e romântica trataram de abordar os elementos locais, porém com uma estética tida por muitos desses historiadores como excessivamente presa à literatura europeia, sobretudo à literatura portuguesa.

O modernismo encetado pela Semana da Arte Moderna de 1922 teve por paradigma a poesia de Oswald de Andrade e de Mário de Andrade. Em linhas bastante gerais, podese afirmar que essa poesia possui cunho nacionalista, antilusitano, futurista, cubista, experimental, urbano, muitas vezes teorizada por manifestos e poemas metalinguísticos, e ligada às elites paulistas, as quais assumiram o domínio econômico e político do país. Visto que boa parte da sociologia, bem como da crítica literária, as quais desenharam contornos da identidade nacional, também era paulista, urbana e do início do século XX (ligada à expansão da Universidade de São Paulo), logo esse modernismo mais

2 Para Stuart Hall (2006, p. 54), o mito fundacional apresenta-se como "uma estória que localiza a origem da nação, do povo e do seu caráter nacional". Amparado em Bhabha, Hall assume a ideia de nacionalidade como "uma forma de afiliação social e textual" (Bhabha 2013, p. 228). Pensar acerca de um nacionalismo literário implica, portanto, compreender as obras que são referenciais nesse sistema de afiliação intertextual. 
vanguardista e experimental foi tido como o grande grito de independência cultural do país.

Assim, Oswald e Mário são geralmente propagados como os precursores; Drummond, Bandeira e $\mathrm{Cabral}^{3}$ como a maturidade de uma lírica ligada à cultura nacional. Por esse motivo, uma poesia urbana ${ }^{4}$, de bastante experimentação formal, com traços de oralidade, espontânea, humorada, por vezes ensaística, com toques sociológicos na observação da cultura nacional, foi a imagem que importantes críticos literários como Antonio Candido, Alfredo Bosi, Otto Maria Carpeaux, Afrânio Coutinho, entre outros, associaram à poesia brasileira.

Nesse sentido, observa-se os poemas "Erro de português" e "Pronominais", ambos de Oswald, frequentemente citados como exemplos da ruptura modernista que levaria a Drummond, Bandeira e Cabral:

\section{Erro de português}

Quando o português chegou

Debaixo duma bruta chuva

Vestiu o índio

Que pena! Fosse uma manhã de sol

O índio tinha despido

O português

(ANDRADE, 1974, p. 177)

3 Embora Cabral se afaste da linhagem de Andrades, Drummond e Bandeira em alguns aspectos.

4 O caráter urbano dessa poesia e de seus autores não impede a tematização de elementos rurais, sobretudo em Drummond, Bandeira e Cabral. 


\section{Pronominais}

Dê-me um cigarro

Diz a gramática

Do professor e do aluno

E do mulato sabido

Mas o bom negro e o bom branco

Da Nação Brasileira

Dizem todos os dias

Deixa disso camarada

Me dá um cigarro

(ANDRADE, 1974, p. 125)

Ponto importante a destacar em ambos os poemas é a releitura da história colonial envolvendo Brasil e Portugal. Em "Erro de português", essa releitura ocorre por meio da paródia bem humorada dos relatos de viagem do século XVI; em "Pronominais", por meio da discussão envolvendo a colocação pronominal na língua portuguesa brasileira e na língua portuguesa europeia. Assim, a ironia, os versos curtos e imagéticos, o tom narrativo e certo cunho ensaístico são marcas do Modernismo de 1922, sobretudo em Oswald e Mário, naturalizadas como expressão de uma cultura nacional.

Como bem destaca o crítico literário Arnaldo Saraiva (2004), o modernismo brasileiro é bastante distinto do modernismo português preconizado pelos orphistas. O simbolismo de um Cesário Verde ou de um António Nobre foi fundamental para a renovação da poesia defendida por nomes como Mário de Sá-Carneiro ou Fernando Pessoa. 
Pessoa (1986, p. 298) deixa claro que o movimento do fim do século XIX é oriundo de uma tripla natureza, entre as quais o caráter inovador, que seria caro ao Orpheu: "Uma decadência do romantismo. Um movimento de reação contra o cientismo. Um estádio na evolução (ou o princípio duma evolução) de uma nova arte".

No Brasil, contudo, o simbolismo foi bastante associado ao parnasianismo e visto pelo discurso do Modernismo de 22 como uma arte atrasada, acadêmica, intelectual, presa à tradição, etérea (e, por isso, afastada do cotidiano e da realidade nacional). Há ainda, é claro, uma questão política: o simbolismo brasileiro esteve ligado à manifestação cultural de elites de estados que não são centrais economicamente e politicamente, como Minas Gerais, Santa Catarina e Rio Grande do Sul. Ronald de Carvalho, por exemplo, tido como um poeta simbolista no Brasil, a quem pouca relevância é concedida, foi colaborador da revista Orpheu em Portugal. Pessoa e Sá-Carneiro viam em Ronald uma modernidade poética que Oswald e Mário não viam.

Isso explica, em parte 5 , o fato de Cecília estar às margens do cânone literário nacional ${ }^{6}$. Cecília estreou na poesia 5 “Em parte" porque é latente outro aspecto: o papel do preconceito de gênero na constituição dos cânones nacionais (SCHMIDT, 2014).

6 A ideia de margem assume aqui um importante significado: Cecília está no cânone, mas não em seu centro. Está, antes, em uma zona liminar em que sua obra é aceita, porém não lhe é conferida a devida relevância. 
fortemente ligada ao simbolismo, característica que a acompanhou ao longo de toda obra, embora de maneira esparsa ou diluída em formas mais livres com o passar dos anos. A musicalidade; o gosto pelo soneto; o misticismo; a religiosidade; a reflexão filosófica; a passagem do tempo; o tom triste, melancólico e introspectivo; as referências à tradição portuguesa; a ausência de um discurso nacionalista mais inflamado, são características que tornam a lírica de Cecília bastante distinta daquilo que se consagrou denominar modernismo brasileiro e, de certa forma, próxima do que se consagrou denominar simbolismo no país. Ela, Murilo Mendes, Jorge de Lima e Augusto Frederico Schmidt são corpos tidos como "estranhos" no início do século XX, os quais deixaram nitidamente desconfortáveis críticos e historiadores da literatura ${ }^{7}$.

Dois dos poemas de Cecília mais recorrentes em historiografias, materiais didáticos e aulas de literatura brasileira são "Retrato" e "Auto-retrato". Comparar esses textos com aqueles escritos pelos expoentes de 22 torna evidente o seu desencaixe na narrativa de uma história da literatura com caráter nacional.

7 Alfredo Bosi (2006, p. 493), por exemplo, destaca em Cecília "a atenção à riqueza do léxico e dos ritmos portugueses". Os elementos destacados (riqueza lexical e musicalidade portuguesa) são aqueles opostos ao projeto poético de Oswald ou de Mário. 


\section{Retrato}

Eu não tinha este rosto de hoje, Assim calmo, assim triste, assim magro, Nem estes olhos tão vazios, Nem o lábio amargo.

Eu não tinha estas mãos sem força, Tão paradas e frias e mortas;

Eu não tinha este coração Que nem se mostra. Eu não dei por esta mudança, Tão simples, tão certa, tão fácil: - Em que espelho ficou perdida a minha face?

(MEIRELES, 2006, p. 19)

\section{Auto-retrato}

Se me contemplo tantas me vejo, que não entendo quem sou, no tempo do pensamento. Vou desprendendo elos que tenho, alças, enredos... Formas, desenho que tive, e esqueço! [...] (MEIRELES, 1983, p. 224)

O par de poemas aborda uma das questões mais relevantes do início do século $X X$, a crise de identidade do sujeito moderno. Em "Retrato", o eu-lírico, frente à sua imagem do passado, não se reconhece. São constituídos no poema, assim, dois eus confrontados, opostos, incompatíveis. Em 
"Auto-retrato", ao procurar definir sua imagem, o eu-lírico não consegue, pois é muitos. Os limites linguísticos de um eupoético que busca definir-se em versos, porém não consegue reduzir-se a uma imagem por ser fragmentado ou plural, é recorrente em muitos poemas da autora. Em "Lua adversa" (MEIRELES, 1983, p. 197), por exemplo, a comparação com a lua apresenta as diferenças do eu-lírico em relação a si ao longo do tempo: "Tenho fases, como a lua, / Fases de andar escondida, / fases de vir para a rua...". Em "Mulher ao espelho", o espelho revela no eu-lírico não uma mulher, mas mulheres: "Já fui loura, já fui morena, / já fui Margarida e Beatriz. / Já fui Maria e Madalena" (MEIRELES, 1983, p. 272). Em "Inscrição", há a imprecisão para inscrever-se: "Sou entre flor e nuvem, / Estrela e mar. / Por que havemos de ser unicamente humanos, / Limitados em chorar?" (MEIRELES, 1983, p. 278).

É perceptível que os poemas de Cecília Meireles não possuem o caráter iconoclasta, paródico, anticlássico, sociológico, nacionalista e irônico que permeou o grupo de 22. No entanto, a problematização existencial situada entre o eu, a alteridade e a linguagem é pauta bastante importante naquilo que podemos definir como "poesia moderna" (FRIEDRICH, 1978). Nesse aspecto, a modernidade da poesia 
ceciliana dialoga mais com a modernidade dos poetas portugueses do início do século XX. Em Florbela Espanca (2010, p. 127), há um eu que se anuncia na indefinição de nuvens, névoas, brumas, névoas, "talvez a visão que Alguém sonhou". Em Sá-Carneiro, lamenta a voz poética: "Perdi-me dentro de mim / Porque eu era labirinto / E hoje, quando me sinto, / É com saudades de mim" (1996, p. 36). Álvaro de Campos (PESSOA, 2006, p. 180), em simbiose com a fumaça de seu cigarro, confunde-se com a paisagem da janela, com a tabacaria, com a tabuleta, com o Esteves, com os comboios, e, à parte não ser nada, carrega em si todos os sonhos do mundo.

Talvez Cecília fosse lembrada modernista em Portugal. Talvez fosse considerada orphista, sensacionista etc. - não fosse o caráter misógino do período, é claro. Se não alinhada a Orpheu e definida modernista pelas historiografias, possivelmente fosse referida como uma poeta importante para a constituição e consolidação da lírica moderna, tal qual Florbela ou, mais adiante, Sophia de Mello. Não há como saber. Mas é possível constatar que a modernidade de sua obra, dialogando com o simbolismo e abordando em tom existencial a crise identidade do início do século, é próxima da modernidade dos poetas portugueses. Não à toa, significativa 
parte da crítica literária reduziu Cecília por não se enquadrar nos estereótipos de uma poesia nacional brasileira.

Antonio Candido, por exemplo, o maior crítico literário do Brasil, pouco falou sobre Cecília Meireles em suas centenas de textos. Alfredo Bosi (2006) considerou-a uma poeta distanciada da realidade social em tom de fuga e sonho. Gilberto Teles (2009), grande estudioso dos modernismos, não aborda a obra da poeta em sua coletânea sobre vanguarda europeia e modernismo brasileiro. Contemporâneo de Cecília, o crítico Agrippino Grieco (1932, p. 202) taxou-a pouco original, imitadora de Antero de Quental, a quem faltaria alegria, esperança e lirismo.

O crítico português Nuno de Sampaio, em texto de 1949, chegou a considerar Cecília "pouco brasileira", dado o tom introspectivo e filosófico de sua obra, conforme aponta Maria Lúcia DalFarra:

Trago para aqui, para confirmar tais hipóteses, o parecer de Nuno de Sampaio, quando comenta o êxtase presente na obra de Cecília, que ele qualifica de "místico", aproximando-o a uma tradição muito mais européia que brasileira. Nocaso deseroriundo do Brasil, em tal êxtase imperaria, segundo ele, uma sensualidade tropical - coisa que não ocorre com Cecília. Sublinhando, pois, a diferença lírica de Cecília, ele assegura, por fim, que a sua poesia transfiguradora 
e sobrenatural acerca-se mais do cunho de qualquer poeta nórdico que da sensualidade tropical da também brasileira Adalgisa Neri, outra grande poetisa: esta ama cada forma, tudo que toca, tudo que acaricia; cada coisa Ihe diz: "Adalgisa!", o que nunca aconteceria a Cecília Meireles, pois se uma acaricia e permanece (tropicalismo indolente e sensual), a outra reduz e ascende (atavismo europeu que Cecília constantemente relembra). (DALFARRA, 2006, n.p.)

Outro importante crítico português que parece reduzir Cecília a uma série de estereótipos nacionais e de gênero é João Gaspar Simões. Apesar de ser admirador de sua poesia e já a ter considerado "um dos maiores poetas de língua portuguesa de todos os tempos" (SIMÕES, 1950, p. 3) ${ }^{8}$, considera-a menos brasileira e menos mulher por sua intelectualidade:

Nada sensual na sua expressão, pelo menos sem sensualidade à flor da pele, muito mais intelectual do que qualquer outra escritora da nossa língua, Cecília Meireles, que, lida à portuguesa, sobretudo desde que os seus versos adotaram metros clássicos tratados à moderna - a rima branca e o ritmo surdo - parece sem sexo, desprendida de corpo e alma do que no corpo e na alma é frêmito terreno - lida à brasileira, logo ganha corpo e alma, corpo e alma de mulher, tão muscularmente carnal, no fim de contas é a música dos seus versos. (SIMÕES, 1950, p. 10)

8 Simões usa o masculino para se referir à importância de Cecília enquanto poeta, como se a grandeza e o poético fossem incompatíveis com o feminino. Esse uso do masculino para se referir a mulheres poetas de grande relevância foi comum na primeira metade do Século XX. 
De acordo com Robert Stam, "os estereótipos constituem um instrumento pelo qual as pessoas caracterizam, de maneira necessariamente esquemática, outro grupo com o qual estão apenas parcialmente familiarizadas" (2008, p. 456). No caso, a representação do que venha a ser o brasileiro passa pelas ideias de corporeidade, de sensualidade, de extravagância, de extroversão - os mesmos estereótipos repercutidos ao longo da história colonial (BHABHA, 2013). Ao colonizador, caberia o esquema imagético oposto: racional, comedido, reservado, introspectivo e intelectual.

Nesse sentido, a literatura que não se apresenta corpórea, sensual, extravagante e extrovertida é vista, tradicionalmente, tanto por portugueses como por brasileiros, como "menos brasileira" ou "mais europeia/ portuguesa". Ademais, à mulher colonizada foram impostos mais estereótipos: passional, desmedida, incompreensível, corpórea. A poesia de Cecília, definitivamente, não cabe nessas imagens coloniais a respeito da mulher brasileira perpetradas nas identidades nacionais.

É por esse motivo que Roberto Acízelo de Souza (2018) aponta, em Historiografia da literatura brasileira, para os problemas do recorte nacional na historiografia literária. A construção e evolução de uma disciplina que condicionou a leitura literária à representação nacional hegemônica, tanto 
no país quanto fora dele, fez com que poetas como Cecília Meireles, com traços intimistas, melancólicos, filosóficos, religiosos, viajantes, de diálogo com tradições literárias de outros países, despreocupada com a temática nacional, fossem vistos como "menos brasileiros" e, por isso, menos dignos de figurar nas representações de uma literatura brasileira. Daí a importância de uma leitura comparativa dos textos literários, críticos e teóricos, canônicos ou não, a respeito da nação. De acordo com a comparatista Tânia Franco Carvalhal (1997), só assim será possível colocar o nacional em questão, ao invés de abordar a questão do nacional.

À parte a problemática da relação entre a obra lírica de Cecília e o imaginário do que venha a ser poesia nacional e feminina para a historiografia literária brasileira, está o caso de $O$ romanceiro da Inconfidência, de 1953. Ao recuperar um gênero inusitado para o século $X X$, o romanceiro, Cecília confirma seus interesses pela literatura medieval e pela tradição ibérica. O poema, composto por 85 romances, toma como matéria a Inconfidência Mineira, a mais marcante revolta separatista de uma região do Brasil em relação à Coroa Portuguesa.

Dada sua inspiração iluminista, a Inconfidência não era apenas um movimento político, mas intelectual, científico e 
artístico, ligado aos ciclos árcade e barroco da cidade de Vila Rica. Importantes lideranças da Inconfidência, como Tomás António Gonzaga, Cláudio Manuel da Costa e Alvarenga Peixoto eram os principais expoentes da poesia árcade local. Coube a eles, portanto, as referências intertextuais do Romanceiro de Cecília, bem como os momentos líricos de sua narrativa, os quais retratam amores poéticos pastoris.

O caráter épico do texto está, sobretudo, na trajetória de Tiradentes. Simples alferes do exército, este era o líder de origem mais popular do levante. Após a coroa reprimir o movimento, condenando os inconfidentes de origem portuguesa e de classe alta ao desterro, Tiradentes foi executado em público. A morte desse herói popular em nome de causas coletivas e locais é, portanto, o clímax épico da narrativa de Cecília - como pode ser evidenciado no "Romance 60", que trata do seu caminho solitário até a forca (MEIRELES, 2012, p. 161).

Apesar do inusitado resgate do gênero romanceiro, essa obra de Cecília, uma narrativa histórica, vai ao encontro das inclinações nacionalistas da crítica literária mais tradicional. Se essa é centrada em um mito literário baseado na ruptura com Portugal, Cecília oferece justamente a consagração literária do primeiro movimento separatista brasileiro. Se 
Antonio Candido (2012) considera o arcadismo mineiro como o primeiro momento de um sistema literário que possa ser considerado efetivamente brasileiro, $O$ romanceiro liga o presente modernista a um pretenso passado de origem nos referidos poetas árcades. Isso explica, portanto, o entusiasmo da crítica com relação a essa obra, ao mesmo passo que explica também o silenciamento de obras líricas importantíssimas, como Viagem e Mar absoluto.

Sob essa ótica, parece que a crítica literária brasileira, ao menos a mais badalada e prestigiada, segue cometendo o mesmo erro denunciado por Machado de Assis (1973) em seu ensaio "Notícia da atual literatura brasileira: instinto de nacionalidade". No texto, Machado denuncia a necessidade de abordagem daquilo que chamou "cor local" para uma obra ser considerada representativa do país. No século $X X$, altera-se apenas a "cor local" pelas "imagens hegemônicas da nação".

Se os críticos mencionados esconjuram Cecília da pátria que constroem em seus escritos, os próprios poetas acolhem Cecília como conterrâneos, concidadãos, irmãos de uma pátria outra, a qual não tem lugar nos limites territoriais do Estado-Nação.

Mário de Andrade (1946), em entusiasmado artigo em que analisa a obra Viagem, caracteriza a poesia ceciliana por um "sábio ecletismo" e considera-a detentora de um 
dom especial, um "dom raro". Conclui afirmando que o livro concretiza Cecília como um dos maiores poetas nacionais ${ }^{9}$. Murilo Mendes, após o falecimento da amiga e inspiradora, dedica-lhe alguns poemas, destacando seu caráter de trânsito enquanto "poeta apoiada ao vento":

"Da Bela Adormecida" ao som da lira Cecília Meireles

- Cecília, você escreve poesias na eternidade?

- Entre água e cristal, apoiando-as no vento. (MENDES, 1994, p. 1469)

Outro importante poeta do século XX que foi admirador confesso de Cecília é Mario Quintana. Em entrevista concedida à Ivete Brandalise, ele (QUINTANA, 1990, s.p.) afirmou que "é a maior poeta brasileira da primeira metade do século". Ao longo de sua obra, Quintana dedicou muitos poemas a Cecília. Um deles é "Extraterrena":

\section{Extraterrena}

Para Cecília Meireles

Nós colhíamos flores de hastes muito longas E cujos nomes nem ao menos conhecíamos...

E nem sequer, também, sabíamos os nossos nomes...

E para quê, se um para o outro éramos Tu, apenas...

Ou quem sabe se a Morte nos houvera bordado

9 Mário de Andrade empregou o masculino para definir a autoria de Cecília, da mesma forma que João Gaspar Simões. 
numa tapeçaria

A que o vento emprestasse a vida por um momento?

E por isso os nossos gestos eram ondulantes como as plantas marinhas

E as nossas palavras como asas suspensas no vento...

(QUINTANA, 2005, p. 761)

Destaca-se, nesses versos, a relação da poesia de Cecília Meireles com o mar e o ar: "gestos ondulantes", "plantas marinhas", "asas suspensas no vento", da mesma forma que Murilo Mendes havia destacado o "apoio do vento".

Talvez seja o poeta Manuel Bandeira (2009, p. 187), em seu trabalho historiográfico intitulado Apresentação da poesia brasileira, quem melhor tenha descrito Cecília: "Há não sei que graça aérea nas imagens de Cecília Meireles, cuja poesia se pode definir por aquele pensamento, aquela música a passar na frescura da 'Noite' e que era 'uma nuvem repleta, entre as estrelas e o vento". Bandeira segue ao dizer que "o poeta era para Cecília Meireles um irmão do vento e da água, deixando seu próprio ritmo por onde quer que vá" (2009, p. 187). Mais uma vez, há destaque para a água e o ar - aquilo que se pode compreender como elementos poéticos menos fixos, pois etéreos, viajantes ou em trânsito. 
A ideia de uma poética das águas e do ar foi desenvolvida por Ana Mafalda Leite (2012) ao analisar a importância dos elementos para a poesia moçambicana. Para a pesquisadora, há na tradição de Craveirinha e Noémia uma poesia da terra e do fogo, a qual pode ser observada na relação telúrica entre corpo negro e espaço africano. Por outro lado, há na tradição de Virgílio de Lemos, Rui Knopfli e Glória de Sant'Anna uma poética das águas e do ar. Uma poesia dada ao Índico e aos fluxos culturais, históricos e geográficos que ele propicia. Ou seja, a poesia da água e do ar moçambicana é uma poesia que busca aliar elementos das culturas locais a elementos estrangeiros, uma poesia em movimento, para além das fronteiras nacionais, a qual busca nas águas oceânicas o seu estatuto poético.

Apesar de Ana Mafalda referir-se à poesia moçambicana e ao Índico, pode-se pensar em uma série de similaridades entre essa poética e a poética de Cecília. Esta é marcada por elementos não sólidos, que escapam às formas fixas, tais como sombras, penumbras, névoas, nuvens, quimeras, espumas, tal como em outros poetas modernos bastante ligados ao simbolismo.

Contudo, o mar parece ser um elemento central entre essas imagens etéreas cecilianas. É justamente em sua potência simbólica, filosófica e cultural que parece residir a 
poeticidade de Cecília. Em "Modinha", por exemplo, é o mar que canta, é ele quem sabe o presente e o passado: "O mar, de língua sonora, / sabe o presente e o passado. / Canta o que é meu, vai-se embora" (MEIRELES, 2001, p. 336).

Mas, para além de ser o lugar do poético, é importante pensar os significados que o mar adquire na obra ceciliana, o que indicaria, inclusive, características de sua lírica marítima. Desse modo, o excerto de "Mar absoluto", pode ser bastante relevante para entender seus sentidos.

\section{Mar absoluto}

Foi desde sempre o mar,

E multidões passadas me empurravam como o barco esquecido.

Agora recordo que falavam da revolta dos ventos, de linhos, de cordas, de ferros, de sereias dadas à costa.

E o rosto de meus avós estava caído pelos mares do Oriente, com seus corais e pérolas, e pelos mares do Norte, duros de gelo. Então, é comigo que falam, sou eu que devo ir. Porque não há ninguém, tão decidido a amar e a obedecer a seus mortos.

(MEIRELES, 1983, p. 219)

Se a crítica literária rotulou a poesia de Cecília como intimista, é importante perceber que a alteridade está 
presente em seus poemas, sendo o mar a via de encontro com o outro. Em "Mar absoluto", o outro é os familiares que já se foram, é o passado, é o Oriente, é o Norte. Já em "Canção" (MEIRELES, 2006, p. 34), por exemplo, o outro intermediado pelo mar é o amado ausente. Nos Doze noturnos de Holanda (MEIRELES, 1986), as águas (nesse caso, fluviais) possibilitam o encontro com o afogado que inquieta o sujeito lírico. Nos Poemas escritos na Índia (MEIRELES, 2014), a viagem marítima leva ao encontro com os bordadores de Cachemir, com Gandhi, com a cultura hindu. Em "Nadador" (MEIRELES, 1956, p. 62), o mar traz o encontro de um olhar poético descritivo com o homem erotizado. O mar poético ceciliano é, em suma, encontro com o outro.

Maria Lúcia DalFarra, uma das críticas literárias que mais produtivamente abordou a lírica de Cecília, destaca a importância do caráter de trânsito, de "exilada sem parada fixa", para a sua obra. Isso corrobora o significado do mar enquanto elemento poético de encontro poético com a alteridade:

Mas é a partir de 1940, dessa nova fase de sua vida, que Cecília recomeça, também, a saga de viagens, deixando de tempos em tempos a aprazível morada de Cosme Velho e a inflexível disciplina de escrita, a fim de conhecer diferentes continentes, percorrendo, ao longo da sua vida, países tais como a Argentina, o Uruguai, a França, a 
Bélgica, a Holanda, a Índia, incluindo Goa, a Itália, Porto Rico e Israel. Tal mapa palpilhado pouco a pouco no encalço de conhecimento de seus povos não era para ela, todavia, simples terras a viajar, mas culturas a serem decifradas, geografia e história a serem apreendidas, experiências poéticas que redundaram em obras que, embora sendo versos de itinerância, são, antes, pura poesia contemplativa. Em verdade, os lugares visitados perfazem, para Cecília, "retratos de uma grande pátria transcendente", desejo de abolição das linhas demarcatórias, terras que ela habita na sua condição de "moradora de uma latitude própria", ela que, naquilo que escreve, exerce a condição de andarilha solitária e de exilada sem parada fixa. (Cf. Sanches Neto, 2001) É o que emana da leitura dos Doze Noturnos da Holanda (1952), dos Poemas escritos na Índia (1953), dos Poemas italianos (1953), de Pistóia, cemitério militar brasileiro (1955) e dos Poemas de viagens (1940-1964). (DALFARRA, 2006, s. p.)

Compreender, então, a itinerância desses versos, que buscam contemplar o outro que também nos constitui, é fundamental para a valorização da poesia de Cecília em seu caráter móvel, não a reduzindo a territórios fixos e préestabelecidos. Assim, volta-se à pergunta norteadora deste estudo: afinal, qual o seu lugar na poesia brasileira? Que lugar uma poeta de "uma grande pátria transcendente", "moradora de uma latitude própria", poderia ter em um recorte nacional? 
Talvez o lugar de Cecília Meireles não seja mesmo a literatura brasileira - ou a literatura brasileira tal qual a construíram os críticos literários sob sua concepção da identidade nacional. Somente em uma abordagem transnacional e comparativa é que se perceberá sua importância para a lírica de língua portuguesa do século XX, ao lado de outros poetas "sem lugar", como Florbela Espanca, Sophia de Mello Breyner Andresen, Virgílio de Lemos, Glória de Sant'Anna, Rui Knopfli e outros.

Cecília Meireles pertence às águas. Seus poemas, em corrente marítima, não têm lugar - como não deve ter a poesia. Quando apreendidos e fixados, já não estão. Já são outra coisa, para logo depois deixar de ser também. Tal como a identidade da poeta, a água não pode ser definida em forma alguma. Por isso a pátria de Cecília não é simplesmente o Brasil onde nasceu ou o Portugal de sua família; a pátria de Cecília é a poesia. É os simbolistas e os modernistas, os medievais e os árcades. É Mário de Andrade, Drummond, Quintana e também Florbela, Pessoa, Sophia. É Mallarmé e também Rilke. É Montalvo e também Tomás António Gonzaga. É África, Índia, Holanda, Itália. Sua pátria é essa pátria sem território, uma pátria móvel, indefinível, de cidadãos sempre estrangeiros, sempre estranhos à própria língua por cantarem para além de suas fronteiras. 


\section{REFERÊNCIAS}

ANDRADE, Mário de. Sobre Viagem. In: ANDRADE, Mario de. $O$ empalhador de passarinho. São Paulo, Livraria Martins Editora,1946. ANDRADE, Oswald de. Obras completas VII: poesias reunidas. Rio de Janeiro: Civilização brasileira, 1974.

ASSIS, Machado de. Notícia da literatura brasileira: Instinto de nacionalidade [1873]. In: ASSIS, Machado de. Obra completa. Vol. III. Rio de Janeiro: Nova Aguillar, p. 801-809, 1973.

BANDEIRA, Manuel. Apresentação da poesia brasileira. São Paulo: Cosac Naify, 2009.

BHABHA, Homi K. Disseminação: o tempo, a narrativa e as margens da nação moderna. In: BHABHA, Homi K. O local da cultura. Tradução de Myriam Ávila, Eliana Lourenço Reis e Gláucia Gonçalves. Belo Horizonte: Editora UFMG, p. 227-273, 2013.

BOSI, Alfredo. História concisa da literatura brasileira. São Paulo: Cultrix, 2006.

CANDIDO, Antonio. Formação da literatura brasileira. Rio de Janeiro: Ouro sobre azul, 2012.

CANDIDO, Antonio; CASTELLO, José Aderaldo. Presença da literatura brasileira: modernismo, história e antologia. Rio de Janeiro: Bertrand Brasil, 1994.

CARVALHAL, Tania Franco. A nação em questão: uma leitura comparatista. In: SCHMIDT, Rita Terezinha (Org.). Nações/ narrações: nossas histórias e estórias. Porto Alegre: Associação Brasileira de Estudos Americanos, p. 293-301, 1997.

COELHO, Nelly Novaes. O "eterno instante" na poesia de Cecília Meireles. Alfa: Revista de Linguística, n. 5/6, 1964. Disponível em: https://periodicos.fclar.unesp.br/alfa/article/view/3232/2959. Acesso em: 26 de maio de 2021. COUTINHO, Afrânio (Org.). A Literatura no Brasil. V - Modernismo. Rio de Janeiro: Sul-Americana, 1970. 
DALFARRA, Maria Lúcia. Cecília Meireles: imagens femininas. Cadernos Pagu, Campinas, n. 27, jul./dez., 2006.

ESPANCA, Florbela. Livro de Mágoas. In: ESPANCA, Florbela. Poesia de Florbela Espanca: Vol. 1. Porto Alegre: L\&PM, p. 123-162, 2010.

FISCHER, Luís Augusto. Reféns da modernistolatria. Revista Piauí. Edição 80. São Paulo, 2013.

FRIEDRICH, Hugo. Estrutura da lírica moderna: da metade do século XIX a meados do século XX. Tradução de Marise Curione, São Paulo: Duas Cidades, 1978.

GRIECO, Agrippino. Evolução da poesia brasileira. Rio de Janeiro: Ariel, 1932. HALL, Stuart. As culturas nacionais como comunidades imaginadas. In: HALL, Stuart. A identidade cultural na pós-modernidade. Tradução de Tomaz Tadeu da Silva e Guacira Lopes Louro. Rio de Janeiro: DP\&A, p. 47-65, 2006.

LEITE, Ana Mafalda. Poéticas do imaginário elemental na poesia moçambicana - entre mar... e céu. In: LEITE, Ana Mafalda. Oralidades \& escritas pós-coloniais: estudos sobre literaturas africanas. Rio de Janeiro: Ed. UERJ, p. 297-305, 2012.

MEIRELES, Cecília. Mar absoluto e outros poemas. Porto Alegre: Livraria do Globo, 1945.

MEIRELES, Cecília. Canções. Rio de Janeiro: Livros de Portugal, 1956. MEIRELES, Cecília. Obra poética. Rio de Janeiro: Nova Aguillar, 1983. MEIRELES, Cecília. Doze noturnos de Holanda e outros poemas. Rio de Janeiro: Nova Fronteira, 1986.

MEIRELES, Cecília. Viagem. eBooksBrasil, 2006.

MEIRELES, Cecília. Romanceiro da Inconfidência. São Paulo: Global Editora, 2012.

MEIRELES, Cecília. Poemas escritos na Índia. São Paulo: Global Editora, 2014. MENDES, Murilo. Poesia completa e prosa. Rio de Janeiro: Nova Aguillar, 1994. MOISÉS, Massaud. História da literatura brasileira. Vol. III: Modernismo. São Paulo: Cultrix, 2001. 
PESSOA, Fernando. Obras em prosa. Rio de Janeiro: Nova Aguilar, 1986. PESSOA, Fernando. Antologia poética. Porto Alegre: Leitura XXI, 2006. QUINTANA, Mario (1990). Mario Quintana: Entrevistado por Ivete Brandalise. Templo Cultural Delfos. Maio de 2013. Disponível em: http:// www.elfikurten.com.br/2013/02/mario-quintana-entrevistado-porivete.html. Acesso em: 30 de dez. de 2020.

QUINTANA, Mario. Poesia completa. Rio de Janeiro: Nova Aguilar, 2005. SÁ-CARNEIRO, Mário de. Dispersão. In: SÁ-CARNEIRO, Mário de. Poemas completos. Lisboa: Assírio \& Alvim, p. 25-52, 1996.

SARAIVA, Arnaldo. Modernismo brasileiro e modernismo português: subsídios para o seu estudo e para a história das suas relações. Campinas: Editora da Unicamp, 2004.

SCHMIDT, Rita Terezinha. A história da literatura tem gênero? Notas do tempo (in)acabado de um projeto. In: MOREIRA, Maria Eunice; KOHLRAUSCH, Regina; JACOBY, Sissa (Orgs.). Anais do X Seminário Internacional de História da Literatura. Porto Alegre: EDIPUCRS, 2014. SILVA, Jacicarla Souza da. Vozes femininas da poesia latino-americana: Cecília Meireles e as poetizas uruguaias. São Paulo: Cultura Acadêmica, 2009. SIMÕES, João Garpar. Epílogo. In: MEIRELES, Cecília. Obra poética. Rio de Janeiro: L. Aguilar, 1958.

SOUZA, Roberto Acízelo de. Historiografia da literatura brasileira: Introdução. São Paulo: É Realizações Editora, 2018.

STAM, Robert. Multiculturalismo tropical: uma história comparativa da raça na cultura e no cinema brasileiros. Tradução de Fernando Vugman. São Paulo: EdUSP, 2008.

TELLES, Gilberto Mendonça. Vanguarda europeia e modernismo brasileiro. Petrópolis: Vozes, 2009.

Gustavo Henrique Rückert Doutor (Universidade Federal do Rio Grande do Sul - UFRGS). Professor (Universidade Federal dos Vales do Jequitinhonha e Mucuri - UFVJM). 
Coordenador do projeto de pesquisa "Pós-colonialismos em Língua Portuguesa: Linguagem, Identidade e Política". http://lattes.cnpq.br/3426796078386126 https://orcid.org/0000-0002-9267-5229 gh.ruckert@gmail.com 